\title{
Soroprevalência de sífilis em doadores de sangue do Centro de Hemoterapia de
}

\section{Sergipe}

\author{
Seroprevalence of syphilis in blood donors at the Hemotherapy Center of Sergipe \\ Seroprevalencia de sífilis en donantes de sangre en el Centro de Hemoterapia de Sergipe
}

Recebido: 22/03/2021 | Revisado: 31/03/2021 | Aceito: 08/04/2021 | Publicado: 18/04/2021

\author{
Weber de Santana Teles \\ ORCID: https://orcid.org/0000-0003-1770-8278 \\ Universidade Tiradentes, Brasil \\ E-mail:arteecura@hotmail.com \\ Paulo Celso Curvelo Santos Júnior \\ ORCID: https://orcid.org/0000-0001-5834-6782 \\ Instituto de Hematologia e Hemoterapia de Sergipe, Brasil \\ E-mail: paulo.curvelo.jr@gmail.com \\ Átila Vieira Santos Melo \\ ORCID: https://orcid.org/0000-0001-7387-6060 \\ Instituto Parreiras Horta, Brasil \\ E-mail: atilavsmelooo@gmail.com \\ Francarlos Barros dos Anjos Junior \\ ORCID: https://orcid.org/0000-0002-5673-026X \\ Instituto Parreiras Horta, Brasil \\ E-mail: francarlos@gmail.com \\ Rute Nascimento da Silva \\ ORCID: https://orcid.org/0000-0002-2719-1623 \\ Universidade Tiradentes, Brasil \\ E-mail: silva_rute@hotmail.com \\ Carla Viviane Freitas de Jesus \\ ORCID: https://orcid.org/0000-0002-7775-6610 \\ Universidade Tiradentes, Brasil \\ E-mail: carlavfj@gmail.com \\ Veronica de Lourdes Sierpe Jeraldo \\ ORCID: https://orcid.org/0000-0001-9813-7969 \\ Universidade Tiradentes, Brasil \\ E-mail: veronica_sierpe@hotmail.com
}

\begin{abstract}
Resumo
Objetivou-se avaliar a soroprevalência de sífilis em doadores de sangue do Hemocentro de Sergipe, no período de 2015 a 2017. O estudo foi realizado através da análise dos registros do Hemocentro de Sergipe obtidos no banco de dados HEMOVIDA. Foram registradas nesses intervalos 77.791 doações, sendo estas submetidas ao teste de VDRL (Veneral Disease Research Laboratory) e teste confirmatório com o ensaio imunoenzimático Enzyme Linked ImmunonoSorbent Assay (ELISA). A prevalência de sífilis encontrada no Hemocentro Coordenador de Sergipe no período analisado foi de $1,4 \%$ valor este parcialmente alto, quando comparado a outros em Hemocentros distribuídos pelo país, sendo maior entre o sexo masculino com 73,7\% com grau de escolaridade ensino médio completo e estado civil solteiro. Embora, o estudo não contemple todo o estado de Sergipe, os resultados obtidos permitem obter uma visão mais ampla sobre a situação da sífilis no estado, contribuindo como importante fonte de dados para os levantamentos epidemiológicos realizados pelos órgãos de saúde e possibilitando a estes o direcionamento de suas ações.
\end{abstract}

Palavras-chave: Treponema pallidum; Epidemiologia; Diagnóstico; Doadores de sangue; Transfusão de sangue.

\begin{abstract}
The objective of this study was to evaluate the seroprevalence of syphilis in blood donors at the Hemocentro de Sergipe, from 2015 to 2017. The study was carried out by analyzing the records of the Hemocentro de Sergipe obtained in the HEMOVIDA database. 77,791 donations were registered in these intervals, which were submitted to the VDRL test (Veneral Disease Research Laboratory) and confirmatory test with the Enzyme Linked ImmunonoSorbent Assay (ELISA) immunoassay. The prevalence of syphilis found in the Coordinating Blood Center of Sergipe in the analyzed period was $1.4 \%$, which is partially high, when compared to others in Blood Centers distributed throughout the country, being higher among males with $73.7 \%$ with educational level. complete high school and single marital status. Although the study does not cover the entire state of Sergipe, the results obtained
\end{abstract}


allow a broader view of the situation of syphilis in the state, contributing as an important source of data for the epidemiological surveys carried out by health agencies and enabling them to direct of your actions.

Keywords: Treponema pallidum; Epidemiology; Diagnosis; Blood donors; Blood transfusion.

\section{Resumen}

El objetivo de este estudio fue evaluar la seroprevalencia de sífilis en donantes de sangre en el Hemocentro de Sergipe, de 2015 a 2017. El estudio se realizó mediante el análisis de los registros del Hemocentro de Sergipe obtenidos en la base de datos HEMOVIDA. En estos intervalos se registraron 77.791 donaciones, las cuales fueron sometidas al test VDRL (Laboratorio de Investigación de Enfermedades Venerales) y test confirmatorio con el inmunoensayo ELISA (Enzyme Linked ImmunonoSorbent Assay). La prevalencia de sífilis encontrada en el Centro Coordinador de Sangre de Sergipe en el período analizado fue de 1,4\%, la cual es parcialmente alta, cuando se compara con otros en los Centros de Sangre distribuidos por todo el país, siendo mayor entre los hombres con 73,7\% con nivel educativo completo alto. escuela y estado civil soltero. Si bien el estudio no cubre la totalidad del estado de Sergipe, los resultados obtenidos permiten una visión más amplia de la situación de la sífilis en el estado, contribuyendo como una importante fuente de datos para las encuestas epidemiológicas que realizan los organismos de salud y permitiéndoles orientar Tus acciones.

Palabras clave: Treponema pallidum; Epidemiología; Diagnóstico; Donantes de sangre; Transfusión de sangre.

\section{Introdução}

A sífilis ou lues é uma doença infecciosa exclusiva dos seres humanos e sem outros hospedeiros naturais conhecidos, causada pela bactéria Treponema pallidum, denominado em 1905 por Schaudinn e Hoffmann. As reações sorológicas da sífilis foram descobertas um ano mais tarde, em 1906, por Wassermann de subespécie pallidum, uma espiroqueta patogênica com condições de baixíssimas concentrações de oxigênio para o seu desenvolvimento, que ficou conhecida no século XV, na Europa, e se tornou uma das principais pragas no mundo por ter rápida disseminação. No Brasil, esta doença chegou no período colonial trazida pelos europeus, que por interesses políticos, buscavam a miscigenação do território, disseminando a doença (Brasil, 2010; Matos Junior \& Andrade, 2020).

Foram estimados cerca de 11 milhões de novos casos de sífilis no mundo em 2010, sendo cerca de 2.4 milhões de casos de sífilis na América Latina e Caribe. Em relação ao Brasil os casos de sífilis têm crescidos entre o ano de 2010 a 2016. $\mathrm{O}$ aumento da sífilis congênita e as taxas de deteç̧ão de sífilis em gestante por mil nascidos vivos cresceram aproximadamente de três vezes nesse período, passando de 2,4 para 6,8 e de 3,5 para 12,4 casos por mil nascidos vivos, respectivamente. Quanto às sífilis adquirida, foi notificado um aumento de 2,0 casos por 100 mil habitantes em 2010 para 42,5 casos por 100 mil habitantes em 2016. Em Sergipe foram notificados 383 casos no ano de 2017 na forma congênita e entre 2013 e 2017 foram confirmados 438 casos de sífilis em gestantes (Coelho et al., 2018).

Atualmente, a pesquisa para sífilis é realizada combinando testes específicos e não específicos, a maioria dos laboratórios têm optado pelo Veneral Disease Research Laboratory (VDRL) teste não específico, que tem menor custo, esse se baseia no uso de uma suspensão antigênica, que é composta por uma solução alcoólica contendo cardiolipina, colesterol e lecitina purificada e utilizando o soro inativado como amostra, assim são detectados anticorpos IgM e IgG contra o material lipídico liberado pelas células danificadas em decorrência da sífilis. E o ensaio imunoenzimático Enzyme Linked ImmunonoSorbent Assay (ELISA) refere-se a reações antígeno-anticorpo detectáveis através de reações enzimáticas, utilizando a enzima peroxidase que catalisa a reação de desdobramento da água oxigenada que resulta no surgimento da cor. Portanto, a reação é revelada em um espectrofotômetro. A quantidade de anticorpos presentes nas amostras é diretamente proporcional à intensidade de cor na reação, ou seja, quanto mais anticorpos estiverem presentes na amostra, maior será a intensidade da cor na placa (Brasil, 2017).

A transfusão de sangue é na atualidade um procedimento terapêutico essencial aos cuidados de saúde e que salva milhões de vidas todos os anos, com isso é de suma importância. A Resolução da Diretoria Colegiada, que estabelece normas no objetivo de validar ou não a utilização dos hemocomponentes para procedimentos hemoterápicos em todo o território 
nacional, foi criada para assegurar o paciente contra risco de contaminação. Esta portaria estabelece que todos os candidatos à doação devem passar, impreterivelmente por uma triagem clínica, antes da coleta e, também, por uma triagem sorológica, antes da liberação do sangue e hemocomponentes para transfusão (Brasil, 2016).

A triagem clínica estabelecida pelo inciso $3^{\circ}$ da Portaria $n^{\circ} 158$, de 04 de fevereiro de 2016, consiste na avaliação do estado de saúde do candidato a doação, por meio de informações sobre o peso, idade, sinais vitais e determinação da hemoglobina. Em seguida é realizada uma entrevista com um profissional da saúde, onde serão analisados alguns hábitos e comportamentos de risco, no intuito de garantir a integridade do doador e receptor (Brasil, 2016).

Após a coleta, a bolsa de sangue contendo $450 \mathrm{ml}$ de sangue total segue para o setor de produção, para a realização da separação dos hemocomponentes, uma amostra retirada no momento da coleta vai para o setor de imunohematologia do doador para realização da fenotipagem ABO RH, pesquisa de anticorpos irregulares (PAI) e pesquisa de Hemoglobina S. Outra amostra segue para a triagem sorológica, onde investiga se existem condições de ser utilizado em transfusões. Sendo assim, são realizados obrigatoriamente testes sorológicos para investigação de agentes infecciosos causadores da Hepatite B e Hepatite C, Doença de Chagas, HIV, HTLV e a Sífilis, sendo esta última realizada desde 1938 (Girello \& Kühn, 2002; Brasil, 2018a).

Por meio de pesquisa realizada por Ferreira et al. (2006) na Fundação de Hematologia e Hemoterapia/Hemocentro do Amazonas (HEMOAM), no período de 2000 a 2004, a prevalência de Sífilis foi de 1,3\%. Em São Paulo essa taxa é de 1,1\% em meio aos candidatos da Fundação Pró-Sangue/Hemocentro de $1^{\circ}$ a 15 de novembro de 2001. No Hemocentro Regional de Cruz Alta - Rio Grande do Sul, entre os anos de 2003 a 2009, a prevalência foi de 0,3\%. O índice variável é provavelmente um reflexo das diferentes realidades existentes na área da saúde de cada região do país, pelo conhecimento e práticas sexuais (Boff et al., 2011).

Com base nessas informações, o presente trabalho possui como objetivo analisar a frequência de doadores positivos para sífilis no Centro de Hemoterapia de Sergipe (HEMOSE), no período compreendido entre janeiro de 2015 e dezembro de 2017.

\section{Metodologia}

Trata-se de um estudo transversal, retrospectivo, realizado por meio da análise dos registros de doadores de sangue do Centro de Hemoterapia de Sergipe (HEMOSE), localizado no município de Aracaju/SE, durante os anos de 2015 a 2017.

As análises sorológicas foram realizadas no Laboratório de Sorologia do Hemocentro Coordenador de Aracaju/SE HEMOSE. Os testes utilizados foi o kit da Architect (Abbott, EUA) que detecta anticorpos antitreponêmicos IgG e IgM (total) por quimioluminescência, totalmente automatizado na detecção de anticorpos específicos seguido, nas amostras reagentes, pelos testes VDRL (WAMA) e FTA-ABS (produzido pela "WAMA", São Paulo) empregados em paralelo para confirmação dos resultados reagentes no primeiro teste.

Os dados foram extraídos do software HEMOVIDA e organizados e classificados no programa Excel 365. Após a organização, a análise estatística deu-se pelo software IBM Statistical Package for the Social Sciences, versão 22.0, utilizando um intervalo de confiança de 95\% ( $\mathrm{p}<0.05)$ para significância estatística. Utilizou-se o teste estatístico Qui-quadrado de Pearson (X2) para comparação da distribuição dos valores a partir de duas variáveis (Gênero X Município; Gênero X Estado Civil; Gênero X Escolaridade). Foram usados os testes Kolgomorov-Smirnov com Correlação de Significância de Lilliefors e Shapiro Wilk para avaliação da normalidade (distribuição dos valores na amostra) das variáveis numéricas (Idade e Quantidade de doações) em relação ao gênero. Após a verificação da não parametria, utilizou-se o teste não paramétrico de U MannWhitney de amostras independentes para comparar a distribuição das variáveis de acordo com o gênero.

O estudo foi aprovado pelo comitê de ética da Universidade Tiradentes, sob parecer número 2.954.787. 


\section{Resultados e Discussão}

O total de doações registradas no presente período foi de 77.791. Deste total, 1,4\% (1.130) das doações apresentaram sorologia positiva para sífilis, observou-se uma maior prevalência para o sexo masculinos sendo 73,7\% (833) e 26,3\% (297) para o feminino. Dos doadores soropositivos, 44,3\% (501) residem na capital Aracaju, enquanto 54,3\% (614) residem no interior do estado e $1,3 \%$ (15) proveniente de outros estados, havendo diferença estatística quando comparado o gênero em relação ao munícipio que reside $(\mathrm{p}<0,05)$ (Figura 1).

Figura 1. Perfil sociodemográfico dos doadores soropositivos para sífilis no Centro de Hemoterapia de Sergipe, entre 2015 e 2017.

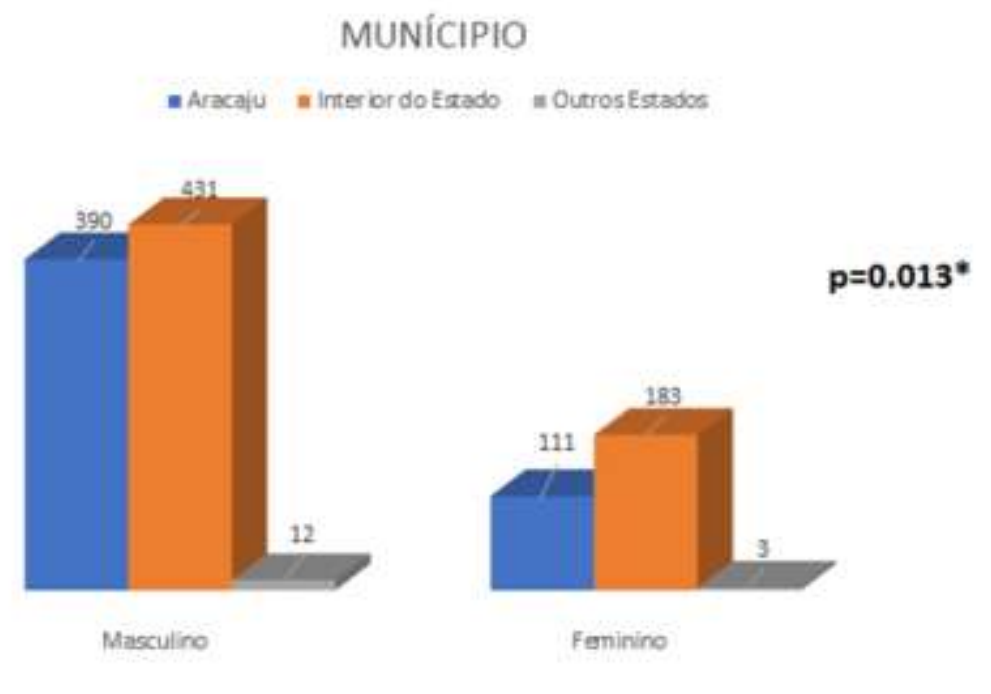

Legenda: * Teste Qui-quadrado de Pearson. Fonte: Autores.

O presente estudo teve um índice de 1,4\% casos de Sífilis, sendo um resultado inferior ao encontrado no período de janeiro de 2004 a dezembro de 2006, nesta mesma instituição onde a prevalência foi de 1,6\% para sífilis (Santos, Marcellini \& Ribeiro, 2008). Os resultados são similares ao encontrado no Hemocentro do Piauí em 2016 onde a taxa foi de 1,41\% (Costa et al., 2016). Em contrapartida, estudo realizado no Hemocentro de Goiás (HEMOGO) a prevalência foi de 0,61\% que é relativamente baixo (Rodrigues, 2012).

A presença de variantes entre os indivíduos pode influenciar na interpretação dos resultados, sendo uma das variantes o gênero, devido à prevalência das doações serem de doadores do sexo masculino por motivos fisiológicos que possibilitem os homens a doarem mais vezes que as mulheres. O resultado vai ao encontro de uma pesquisa realizada por Silva e Cardim (2017) no HEMOLAGOS do Rio de Janeiro, onde mostrou maior frequência de doadores inaptos para sífilis no sexo masculino $(68,4 \%)$, assim como os resultados encontrados no Hemocentro do Piaú, onde 64\% dos soropositivos foram referentes ao sexo masculino (Costa et al., 2016) e observado no serviço de hemoterapia no Rio de Janeiro, em que 72,63\% eram homens (Menezes et al., 2020).

No que se refere ao estado civil, conforme a Figura 2, dos 1.130 doadores soropositivos, 64,3\% (727) eram solteiros, 29,8\% (337) casados e 5,7\% (66) entre divorciados e viúvos, notando-se que houve significância estatística quando relacionado o gênero com o estado civil $(\mathrm{p}<0,05)$. 
Figura 2. Estado civil dos doadores soropositivos para sífilis no Centro de Hemoterapia de Sergipe entre 2015 e 2017.

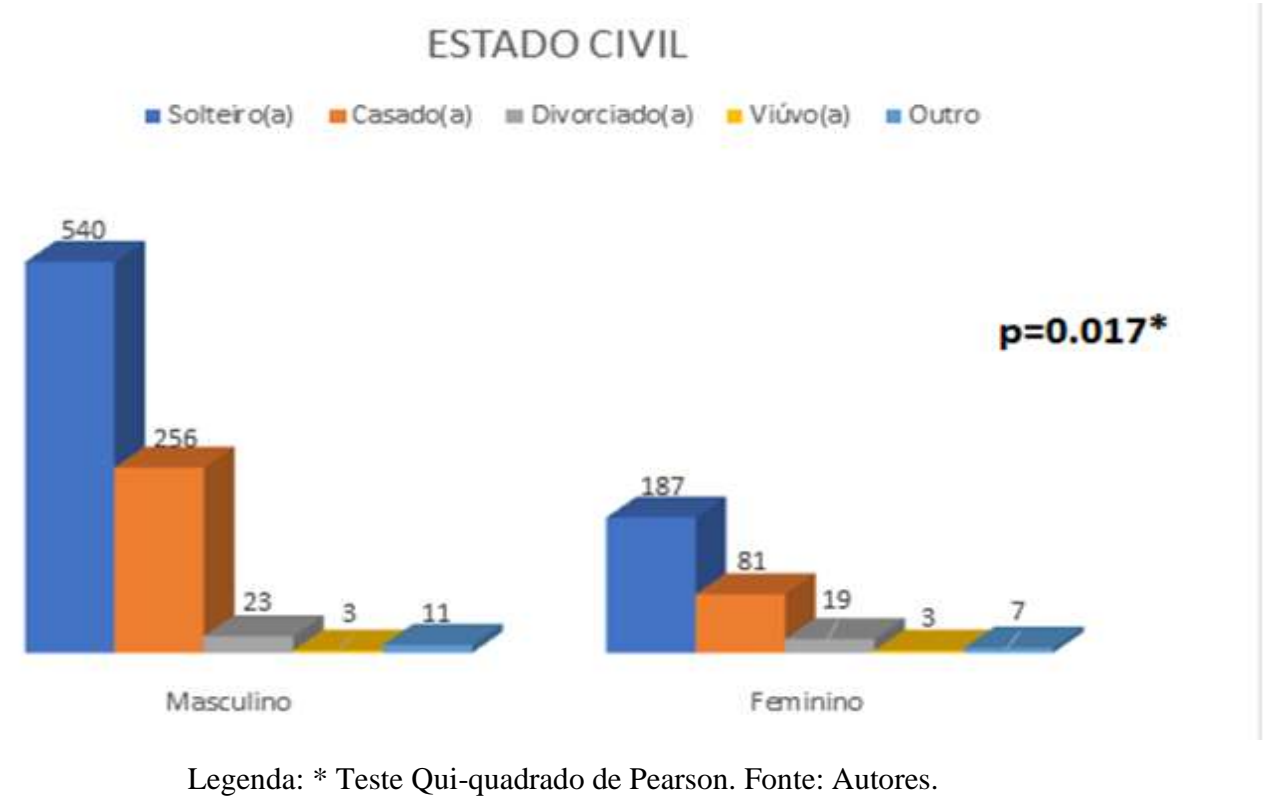

A prevalência entre os solteiros associa ao fator de vulnerabilidade por múltiplos parceiros sexuais. Esse resultado se assemelha ao estudo feito no Hemocentro do Piauí, onde a maior taxa estava entre os solteiros (59,7\%) (Costa et al., 2016). Porém, em outra pesquisa, realizada no Centro de Sangue e Transplantação do Porto, mostrou uma incidência de 53\% entre os casados, enquanto os solteiros foram 30\% (Neto, 2014). Aos casados, essa taxa está relacionada ao fato de se prevenir menos, não apenas no uso do preservativo, mas na menor busca de informação sobre DST do que os solteiros. Portanto, alta frequência pode estar associada a relações extraconjugais sem proteção, trazendo assim maior risco para doenças sexualmente transmissíveis. A negociação do preservativo ainda é um tabu nos relacionamentos estáveis (Fontes et al., 2017; Botton, Cúnico \& Strey, 2017).

A Figura 3 representa os níveis de escolaridades dos soropositivos para sífilis, sendo que ambos os gêneros apresentaram prevalência no segundo grau completo, 28\% (317) masculino e 9,1\% (103) feminino. Em contrapartida, os que menos apresentaram positividade, foram os nãos alfabetizados, sendo 1,3\% (15) homens e 0,2\% (3) mulheres. Notou-se que a distribuição da escolaridade apresentou diferença estatística em comparação com os gêneros (p<0,05) (Figura 4). 
Figura 3. Escolaridade dos doadores soropositivos para Sífilis nos anos de 2015 a 2017 no Centro de Hemoterapia de Sergipe.

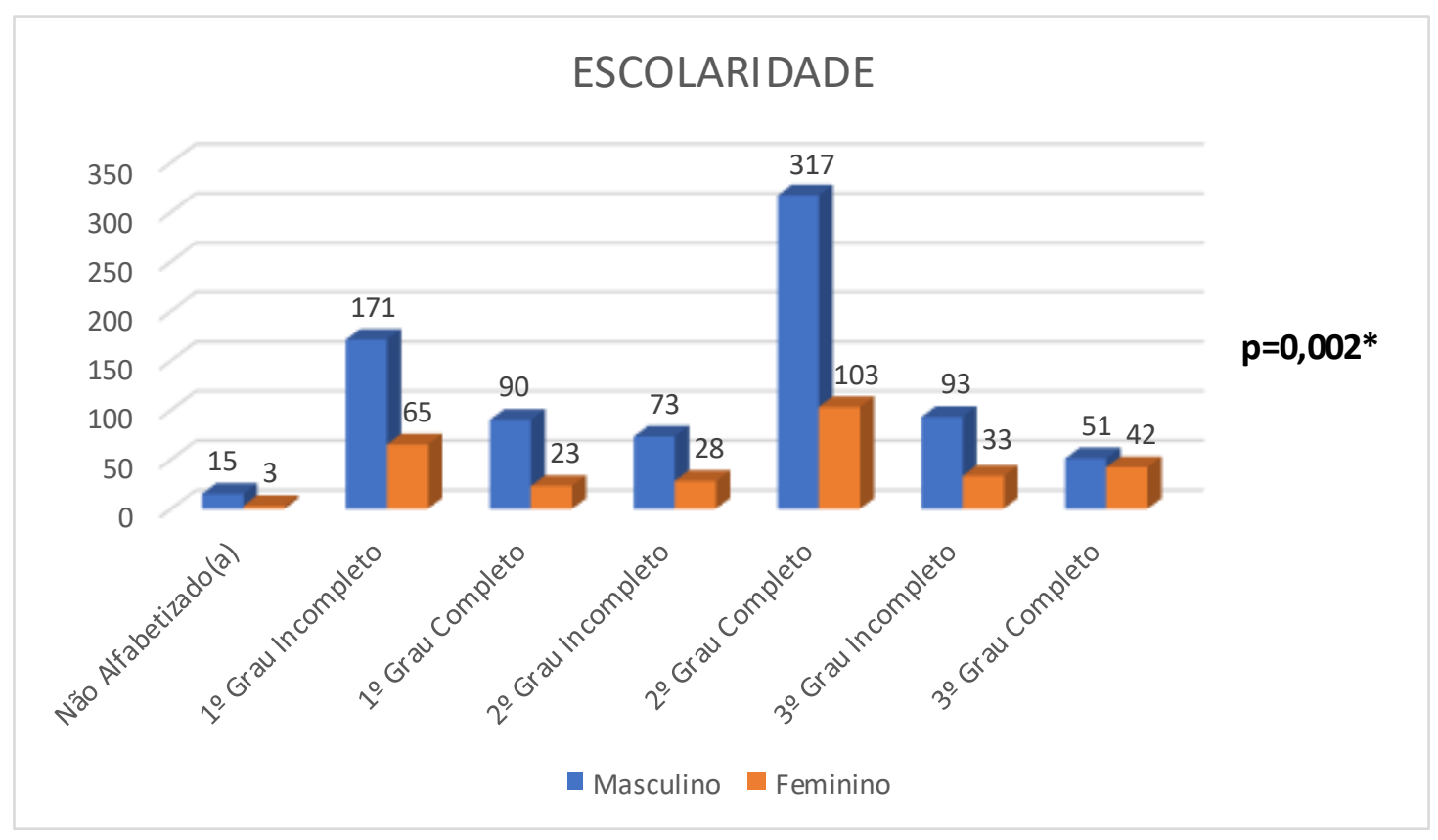

Legenda: * Teste Qui-quadrado de Pearson. Fonte: Autores.

De acordo com o Ministério da Saúde em 2016 dos casos informados, 16,7\% possuíam ensino médio completo, e $21,3 \%$, ensino fundamental incompleto, o resultado desse estudo deve ser analisado levando em consideração que predominam doadores com o ensino médio completo. Logo, é de se esperar que a taxa seja maior entre esses, visto que no Hemocentro do estado do Piauí também predominava soropositividade para os que concluíram o ensino médio (43\%) (Costa et al., 2016). Embora, maior escolaridade está relacionada com menor prevalência de DST, pois a informação pode influenciar a mudança de comportamentos e adoção de práticas sexuais mais seguras, visto que o conhecimento é um fator importante para a prevenção (Farias \& Cavalcanti, 2015).

Analisando a prevalência de sífilis na amostra de doadores em cada ano de estudo, observou-se um decréscimo gradual entre 2015 e 2017 em relação aos casos entre os homens, porém entre as mulheres o índice mostrou-se estável nos três anos (Figura 4). 
Figura 4. Taxa de indivíduos com sorologia positiva para Sífilis nos anos de 2015 a 2017 no Centro de Hemoterapia de Sergipe.

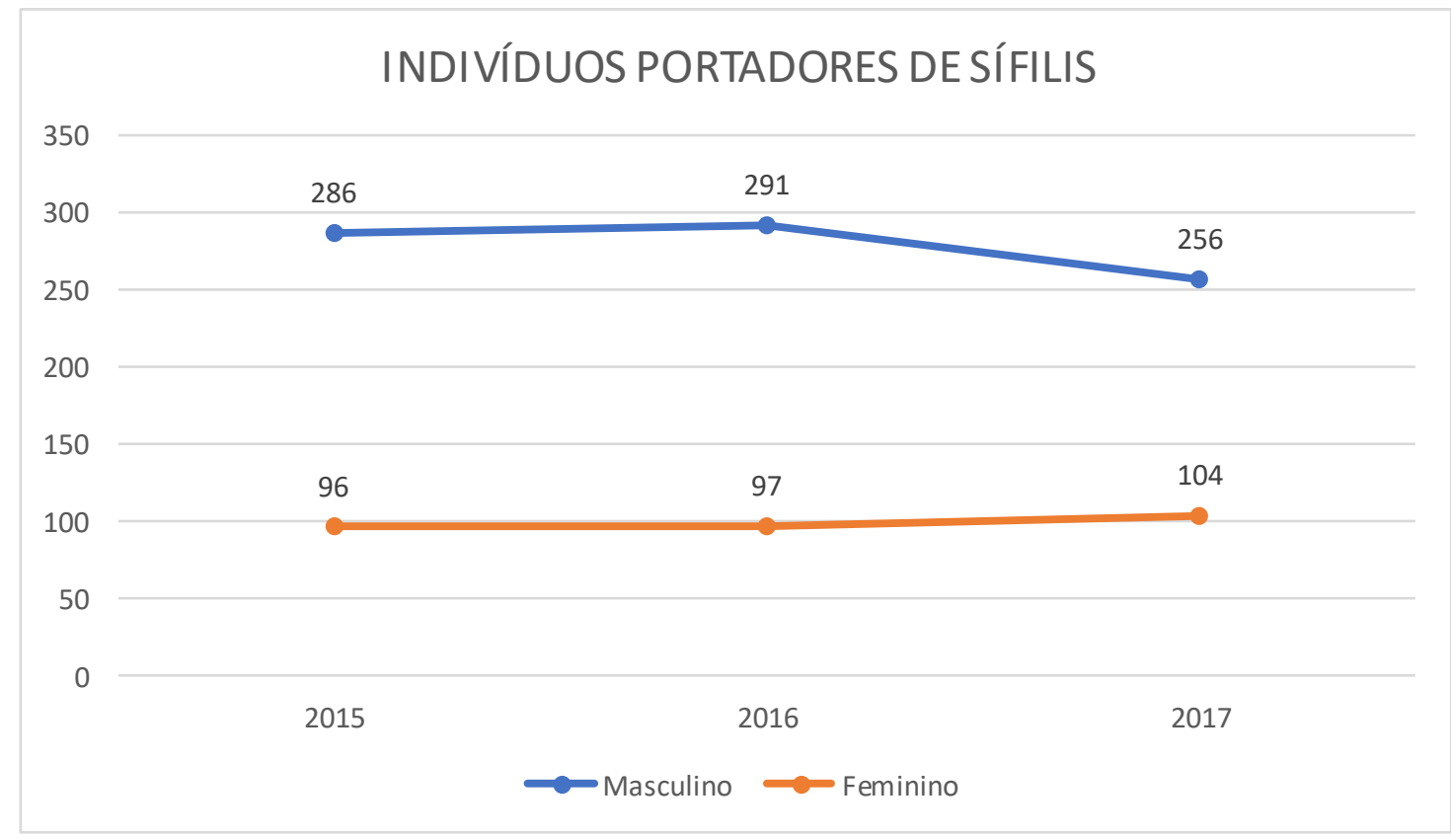

Fonte: Autores.

Sergipe foi o único estado do Nordeste, segundo o Ministério da Saúde, onde a taxa de sífilis adquirida houve um decréscimo expressivo entre 2016 e 2017, passando de 59 casos por 100 mil habitantes para 37,6 casos, sendo o estado de Pernambuco o estado que houve maior crescimento de 16 casos para 26,6 por 100 mil habitantes (Brasil, 2017). Tal fato também foi observado no HEMOLAGOS/RJ em 2015, onde o decréscimo foi de 25.3\%, isso se deve, provavelmente, a adoção de algumas medidas, como a automação dos testes laboratoriais; a adoção de padrões de qualidade; e a realização de campanhas educativas que resultaram no aumento de doadores de repetição, e consequentemente em uma melhor qualidade do sangue disponibilizado para transfusão (Silva \& Cardim, 2017).

Notou-se que o valor central em relação à faixa etária do gênero masculino foi de 35 anos com mínima de 16 e máxima de 69, enquanto o do feminino teve uma mediana de 34 com mínima de 16 e máxima de 61, não apresentando diferença estatística na distribuição dos dados $(\mathrm{p}>0,05)$. Porém, em relação ao total de doações, ambos os gêneros apresentaram mediana semelhantes, todavia divergem na distribuição no quantitativo de doações $(p<0,05)$ (Tabela 1).

Tabela 1. Valores de tendência central dos indivíduos positivos para Sífilis.

\begin{tabular}{ccccc}
\hline VARIÁVEL & \multicolumn{2}{c}{ TERMOS DE TENDÊNCIA CENTRAL } & \multirow{2}{*}{$\mathbf{p}^{*}$} \\
& Mediana & Mínimo & Máximo & \\
\hline Idade & & & & \\
Masculino & 35 & 16 & 69 & 0.134 \\
Feminino & 34 & 16 & 61 & \\
\hline Total de Doações & & & & \\
Masculino & 1 & 1 & 30 & $<0.001$ \\
Feminino & 1 & 1 & 18 & \\
\hline
\end{tabular}

*Teste de U Mann-Whitney. Fonte: Autores.

A média de idade mostrou-se menor quando comparada com os resultados do HEMOLAGOS/RJ no período de 2013 a 2015 onde o valor médio foi de 41 anos (Silva \& Cardim, 2017). Em relação aos dados encontrados no Hemocentro do Piaú 
o valor foi mais distinto com uma tendência central de 47 anos (Costa et al., 2016).

A idade dos indivíduos variou-se entre 16 a 69 anos, essa idade é estabelecida para a aptidão a doação. A análise da faixa etária mostrou uma distribuição heterogênea, sendo maior frequência entre 20 a 40 anos, tanto para as mulheres quanto para os homens, tendo um decréscimo após os 40 anos, não apresentando diferença estatística (p>0,05) (Figura 5).

Figura 5. Distribuição da idade por gênero dos indivíduos positivos para Sífilis.

\section{Gênero}

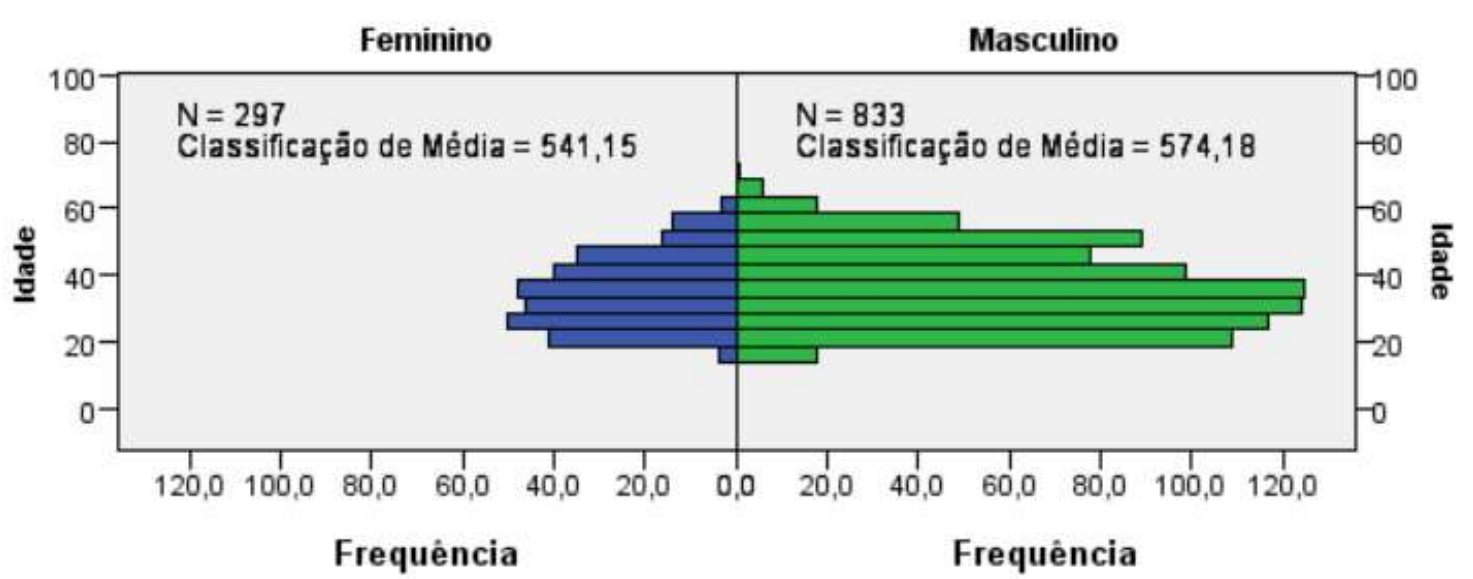

Fonte: Autores.

Segundo o boletim epidemiológico emitido pelo Ministério da Saúde em 2017, a maior parte das notificações em 2016 de sífilis adquirida ocorreu em indivíduos entre 20 e 29 anos (34\%) seguidos dos que tinham entre 30 e 39 anos (22\%). A sorologia não tem nenhuma relação com a idade, porém nota-se nesse estudo uma prevalência na faixa etária de 25 a 40 anos, pois coexiste com a vida sexual mais ativa, podendo o ato sexual desprotegido ser um agravante. O estudo de Marca e Weidlich (2016), no HEMOVALE, Vale do Taquari/Rio Grande do Sul, apresentou resultados similares, visto que o maior quantitativo numérico foi entre os 20 a 30 anos. Contudo, no Hemocentro do Piauí, a frequência foi maior entre 31 a 50 anos com 47,6\% (Costa et al., 2016), assim como no Instituto Português do Sangue onde os casos predominavam sobre os que tinham entre 41 e 50 anos apresentando 35\% (Neto, 2014), indo de encontro aos resultados do presente estudo, apresentando uma diminuição acima dos 40 anos.

Percebeu-se que os sujeitos do sexo masculino tiveram maior índice de doações com relação aos do sexo feminino, notando-se que nas pessoas do sexo feminino houve maior decaimento com o aumento no quantitativo de doações quando comparado ao gênero masculino. Apresentando diferença estatística na distribuição da totalidade das doações em relação aos gêneros $(\mathrm{p}<0,05)$ (Figura 6$)$. 
Figura 6. Distribuição do total de doações por gênero dos indivíduos positivos para sífilis.

\section{Gênero}

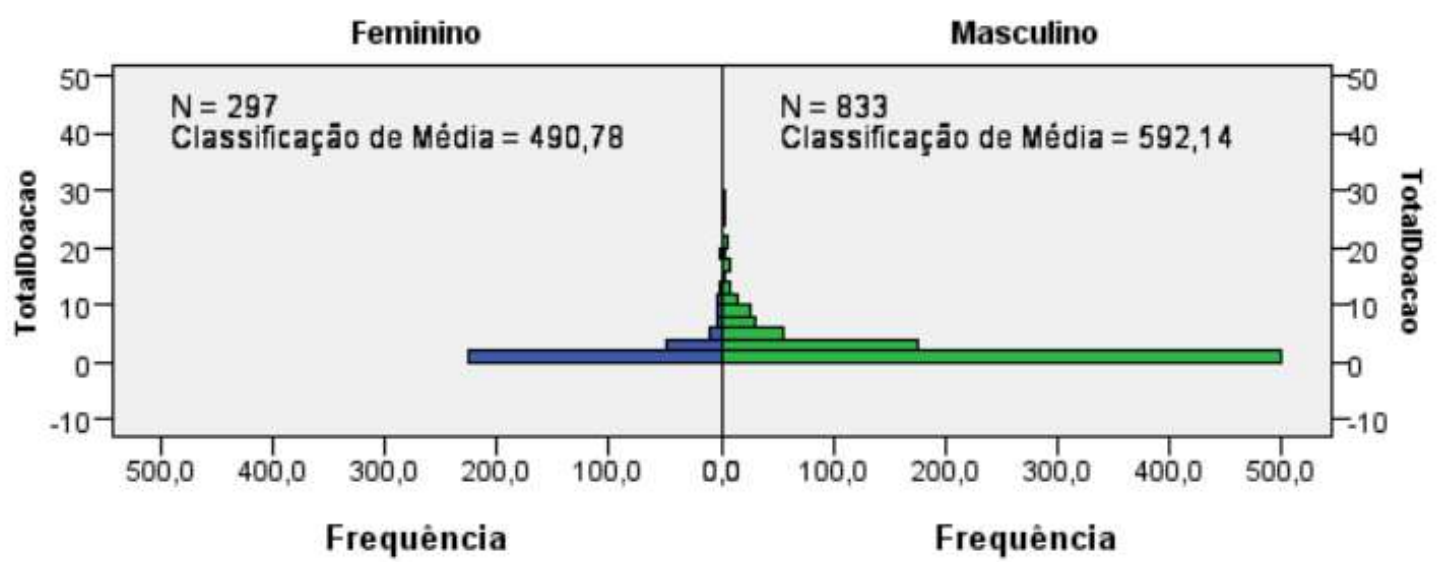

Fonte: Autores.

Com fulcro na análise do número de casos, em relação à frequência, foi constatado que o número de soropositivos em doadores de primeira vez é superior aos doadores regulares, sendo no sexo masculino mais frequente, tendo um decréscimo gradual em ambos os sexos, de modo que, mais notório no feminino, como já relatado em Boletim de Produção Hemoterápica (Brasil, 2018b). Esta análise é semelhante ao estudo realizado em Portugal, onde a maioria dos casos reportavam-se nos doadores de primeira vez com uma taxa de 109 para 100 mil habitantes (Neto, 2014).

\section{Conclusão}

Os resultados obtidos no Hemocentro de Sergipe (HEMOSE) demonstraram que a taxa para sífilis é maior que alguns hemocentros do Brasil, tendo o maior pico em 2016 e apresentando decréscimo em 2017. Em sua maioria, os resultados reativos foram indivíduos do sexo masculino homens solteiros, com idade média de 35 anos, sendo grande parte moradores do interior do estado de Sergipe e com ensino médio completo. Esse perfil é similar aos encontrados em outros hemocentros. Sendo assim, o presente trabalho fornece informações necessárias para a avaliação dos riscos de transmissão de sífilis por meio de transfusões.

Com isso é importante a realização de campanhas descentralizadas no combate às doenças prevalentes na triagem sanguínea, a fim de informar a população sobre formas de prevenção da doença, tal como incentivar adoção de práticas sexuais seguras, procurando melhorar a qualidade e segurança do sangue usado na transfusão.

\section{Referências}

Boff, D., Lunkes, D. S., Kunzler, A., \& Rohr, J. I. (2011). Prevalência de VDRL reagente em doadores do Hemocentro Regional de Cruz Alta-RS, Brasil, no período de 2003 a 2009. Revista de Patologia Tropical/Journal of Tropical Pathology, 40(2), 179-184.

Botton, A., Cúnico, S. D., \& Strey, M. N. (2017). Diferenças de gênero no acesso aos serviços de saúde: problematizações necessárias. Mudanças-Psicologia da Saúde, 25(1), 67-72.

Brasil. Ministério da saúde. (2010). Sífilis: Estratégias para Diagnóstico no Brasil. Coordenação de Doenças Sexualmente Transmissíveis e Aids. 100 p. (Série TELELAB).

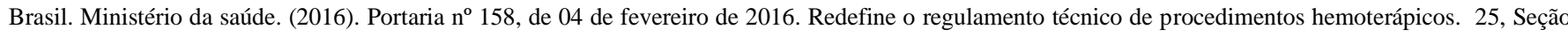
1 .

Brasil. Ministério da Saúde. (2017). Secretaria de Vigilância em Saúde. Boletim Epidemiológico - Sífilis. 48(36). 
Brasil. Ministério da Saúde. (2018a). Secretaria de Atenção à Saúde. Departamento de Atenção Especializada e Temática. Caderno de informação: sangue e hemoderivados. Brasília, (DF): MS, 2018. https://bvsms.saude.gov.br/bvs/publicacoes/caderno_informacao_sangue_hemoderivados_2016.pdf?source=p ost_page

Brasil. Ministério da Saúde. (2018b). Agência Nacional de Vigilância Sanitária. $6^{\circ}$ Boletim de Produção Hemoterápica. Hemoprod. Brasília, (DF): MS, 2018. Recuperado de http://portal.anvisa.gov.br/documents/4048533/4993603/6\%C2\%B0+Boletim+de+Produ\%C3\%A7\%C3\%A3o+Hemoter\%C3\%A1 pica++Hemoprod+2017/15545fd5-ad1f-4b00-9340-a811aa910bbc.

Coelho, J. M. R., Dantas, F. C. S., Pena, L. T. G., Barbosa, J. J., Costa, C. M., Ferreira, L. I., \& Meira, F. B. (2018). Sífilis: um panorama epidemiológico do Brasil e do município de Volta Redonda/RJ/Syphilis: an epidemiological overview of Brazil and the municipality of Volta Redonda/RJ. Brazilian Journal of Health Review, 1(1), 128-147.

Costa, R. L., Silva, L. E. M., Chaves, T. V. S., Sampaio, J. P. S. et al. (2016). Identificação da soroprevalência de Sífilis em bolsas de sangue do Hemocentro do Piauí. Revista Meio-Norte de medicina laboratorial, 2(1), 1-2.

Farias, I. A., \& Cavalcanti, D. G. K. (2015). Estudo da prevalência de doenças sexualmente transmissíveis entre mulheres em idade fértil atendidas em Estratégia de Saúde da Família de Acari/RN. Biota Amazônia (Biote Amazonie, Biota Amazonia, Amazonian Biota), 5(1), 1-6.

Ferreira, C. M., Ferreira, W. A., Motta, C. L., Vasquez, F. G., \& Pinto, A. F. (2006). Reatividade do teste VDRL em bolsas de sangue da fundação de hematologia e hemoterapia do Amazonas-hemoam, os custos decorrentes de descarte e a estimativa de prevalência de sífilis em doadores de sangue do estado do amazonas. DST j. bras. doenças sex. transm, 14-17.

Fontes, M. B., Crivelaro, R. C., Scartezini, A. M., Lima, D. D., Garcia, A. D. A., \& Fujioka, R. T. (2017). Determinant factors of knowledge, attitudes and practices regarding STD/AIDS and viral hepatitis among youths aged 18 to 29 years in Brazil. Ciencia \& saude coletiva, 22, 1343-1352.

Girello, A. L., \& Kühn, T. I. B. (2002). Fundamentos da imuno-hematologia eritrocitária. In Fundamentos da imuno-hematologia eritrocitária (pp. 205-205).

Marca, F., \& Weidlich, L. (2016). Soroprevalência em doadores de sangue do Vale do Taquari, RS. RBAC, 48(3), 240-4.

Matos Junior, S. R. A., \& Andrade, N. B. S. (2020). Enfermeiro como protagonista na segurança transfusional no serviço de hemoterapia: uma revisão integrativa. Caderno de Graduação-Ciências Biológicas e da Saúde-UNIT-SERGIPE, 6(1), 89.

Menezes, R. A., Conceição, M. M. B., Araujo Eleuterio, T., Costa, L. S. L., de Constantino Bandeira, F. M. G., \& da Silva, D. P. C. (2020). Inaptidão clínica e sorológica entre doadores de sangue em um serviço de hemoterapia. Research, Society and Development, 9(10), e2659108486-e2659108486.

Neto, S. R. (2014). Estudo da prevalência de Treponema pallidum na população de dadores de sangue do CSTP-IPST (2010-2014). [Trabalho de conclusão de curso- Instituto Politécnico do Porto].

Rodrigues, M. A. (2012). Soroprevalência de sífilis em doadores de sangue do Hemocentro de Goiás no período de 2002 a 2011 . Bac helor's degree completion. Universidade Estadual de Goiás.

Santos, E. A., Marcellini, P. S., \& Ribeiro, J. P. (2008). Epidemic evaluation of the donors' of blood rejection in Hemolacen/se in period from 2004 to 2006 (Sergipe, Brazil). Rev Bras Anál Clín, 40(4), 251-6.

Silva, I. R., \& Cardim, A. (2017). Perfil epidemiológico dos doadores de sangue inaptos por sífilis. Revista Enfermagem Contemporânea, 6(1), 12-19. 